\title{
Application of medical simulation in the education of medical students in the area of gynecology and obstetrics
}

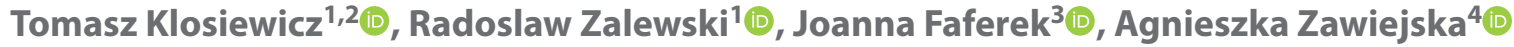 \\ ${ }^{1}$ Poznan University of Medical Sciences, Department of Medical Rescue, Poznan, Poland \\ ${ }^{2}$ Polish Society of Medical Simulation, Poland \\ ${ }^{3}$ Department of Medical Education, Jagiellonian University Medical College, Cracow, Poland \\ ${ }^{4}$ Department of Reproduction, Poznan University of Medical Sciences, Poland
}

\begin{abstract}
The education of new generations of doctors faces major challenges. The education system should ensure access to modern and effective educational techniques. Medical simulation is a method that is developing very dynamically. Currently, every medical university in Poland has access to the facilities of a Medical Simulation Centre. Many types of simulations can be used. The variety of techniques is considerable. Starting from simple trainers, through advanced patient simulators to hybrid simulation or virtual reality. Thanks to their use, it is possible to teach basic medical procedures in a safe way, without compromising the patient's intimacy. An additional advantage is the possibility to train in an interdisciplinary team. The aim of this work was to present the possibility of using medical simulation as a method of effective and interesting teaching of medical students in the field of gynaecology and obstetrics. The authors described different techniques and levels of simulation sophistication. The basic tasks of the teacher were also described. The paper may be an interesting complement to the knowledge of education for each physician involved in the work with students.
\end{abstract}

Key words: high fidelity simulation training; medical education; patient safety; quality of health care; gynaecology

Ginekologia Polska 2020; 91, 5: 281-286

\section{INTRODUCTION}

In interventional specialties, including obstetrics and gynaecology, being on call is necessary to gain skills in dealing with medical emergencies. Young doctors very often simultaneously take shifts in accidents \& emergency (A\&E) department or ambulance. Shifts like this, often called "a school of life", are necessary to gain technical, communicative and decision making skills.

In 2016, according to the Central Statistics Office, 122,000 patients in A\&E where receiving obstetrics and gynaecology treatment. In 2017 this number increased to 127,900 [1]. A good example of this can be hypertensive emergencies. The number of women in Poland suffering from pregnancy-induced hypertension $(\mathrm{PIH})$ is estimated on the level of 30000 per year. Pre-eclampsia is being diagnosed in around $2-3 \%$ of those patients, but there is still a high risk of death for both mother and a child.
On the world scale according to World Health Organization (WHO) $12 \%$ of all maternal deaths is connected to eclampsia. [2, 3]. Placenta previa is one of the most common causes of perinatal complications [4]. Over $50 \%$ of infants delivered in out-hospital setting receive less than 10 points in APGAR scale [5]. Breast cancer is the most frequently recognized cancer among Polish women and is in second place as a cause of death among this group of diseases. In 2012 17,000 of new cases were recognized [6]. The above statistics point out that the ability to recognize maternal or neonatal lethal conditions as well as correct treatment is a real challenge for every doctor, regardless of specialty. The question is if the medical education system is capable to teach students practical skills, which will help them to conquer this challenge?

The main task of medical simulation is to create realistic working conditions, so the student can perform proce- 
dures in a real-time and real-conditions. Clinical education is an inevitable part of medical education but has many limitations. It is not always possible for all students to perform all necessary procedures. Moreover, if a patient is in deteriorating condition, the treatment is often given by the most experienced specialist. As a result, students have limited ability to make their own decisions. It turns out that less than $4 \%$ of residents of obstetrics and gynaecology are confident in their ability to perform procedures without further training. It is estimated that only $28 \%$ of people responsible for training residents in this area believe in the effectiveness of learning using phantoms [7].

The purpose of this paper is to familiarize the reader with the medical simulation as an effective teaching method, that can be used in the process of education of medical students.

\section{MODERN FORMS OF SIMULATION}

The history of using simulation in obstetrics goes back to the late 19th century. Several types of labour simulators were created then, but one of them - the Budin-Pinard phantom was recommended by J. Whitridge Williams in the paper presented at the Congress of the American Medical Colleges. Since then, the use of simulators has become less popular because an increasing number of women were giving birth in hospitals, which gave doctors the opportunity to train skills in real conditions [8].

Although simulation is often associated with teaching resuscitation, its possibilities go much further. It is currently considered one of the most effective methods of education at the pre- and post-graduate level $[9,10]$. The dynamic development of technology has brought new opportunities to use simulations in obstetrics and gynaecology. The degree of the realism of performed activities and environmental conditions is called fidelity of simulation. Fidelity is affected by physical and technical conditions, as well as psychological and environmental factors. In the simplest division we can distinguish the simulation of low and high fidelity.

\section{Low fidelity simulation}

Low fidelity simulation is most frequently used to practically perform a short fragmentary action or procedure. A couple examples of simple evaluations used in gynaecology and obstetrics are breast or gynaecology examination simulators (pelvic). They enable the simulation of appropriate pathology and the analysis of anatomically correct patients. Thanks to such simple verification, the student focuses on the examination itself without the need to communicate with the patient. These simulators are usually made of silicone. The possibilities are wide ranging: from setting the weight of the breast through various types of pressure sensors testing the pressure on the glands. Simulators for gynaecological examination can be complete phan- toms of a woman or only a part of her body. Thanks to such solutions, not only gynaecological examination can be practiced, but also swab collections, performing vaginal ultrasound, learning the correct anatomical structures and various types of pathologies. Simple standards can also be used in conjunction with a standardized patient. This allows creating an advanced and sophisticated scenario, that helps to provide patient-doctor interaction.

There is a wide range of simulators and standards available on the market. The construction of the appropriate phantom and its technological advancement can be selected depending on the level of experience and skills of the students.

Endoscopy is often used in gynaecology. The ability to operate the endoscope especially under the control of a camera image is often used in simulation. These devices allow to acquire psychomotor skills that are necessary to perform procedures, that is why they can be used at various stages of education. A study on the effectiveness of such a method was carried out. A virtual patient was used in resecting the uterine myoma and evaluating the entire procedure. This study showed a significant skills improvement in all training's participants [11].

\section{High fidelity simulation}

High fidelity simulation provides a high level of interactivity and realism for the learner. Nowadays advanced patient simulators are available on the market (HPS, Human Patient Simulator), which in very realistic way can mimic more adequately very specific functions such as physiological and pathological reactions. Modern HPS can imitate presence of the pulse, allows to measure blood pressure, to perform electrocardiography and ultrasonography, to auscultate the chest, examine the abdomen, check pupillary reaction. Seizures, bleeding, sweating, speech, cry, cough or change of the skin colour to cyanotic, pale or yellow can be presented. Neonatal simulators can mimic body movement and muscle tension. Moreover, different pathologies from massive haemorrhage, through eclampsia to cardiac arrest can be presented. There are also complex labour simulators. They have various options for setting and programming scenarios. Focusing only on a delivery, physiological and pathological delivery can be programmed. A child may be born in various positions. Figures 1-3 show various trainers and simulators used to teach the delivery. Adequate simulation type should be chosen based on recipients'knowledge and skills. Introducing very complex simulation cases on the early stages of education, may discourage students from participating in this form of learning. After passing through various stages of teaching activities, knowledge and skills can be combined using increasingly advanced scenarios by moving to high fidelity simulations. Crofts et al. compared 


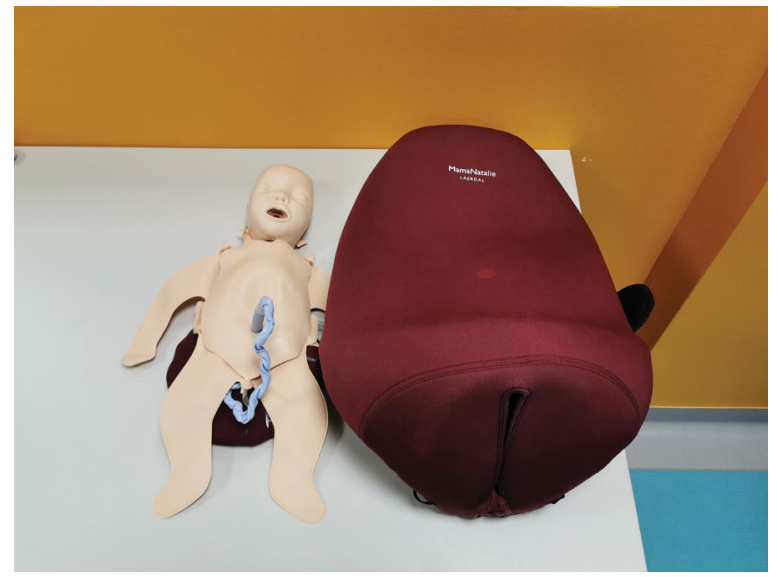

Figure 1. Childbirth trainer for hybrid simulation

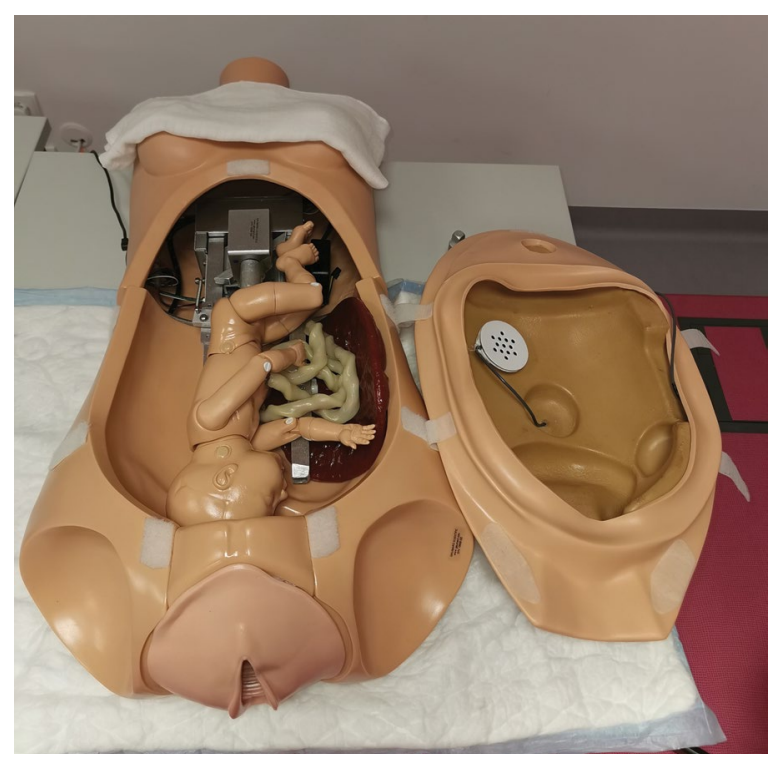

Figure 2. Simple mechanical childbirth trainer

simulation performed with low and high fidelity. Healthcare workers were supposed to deal with shoulder distortion during labour simulation. Both methods improved the results of shoulder dystocia treatment. The use of an advanced simulator gave additional benefits resulting from the possibility of assessing the force used to perform the manoeuvre, as well as communication with the patient [12].

There are also reports of using medical simulation as a tool to check the correct functioning of multi-stage complex medical procedures. Polish research team Puślecki et al. for the first time in Europe, used this method to test the possibility of using extracorporeal membrane oxygenation (ECMO) therapy in a patient after cardiac arrest, respiratory failure and cardiotoxic substances poisoning. In this experiment, one simulator was used at the pre-hospital stage, early hospital care and the operating room. The scope of activities

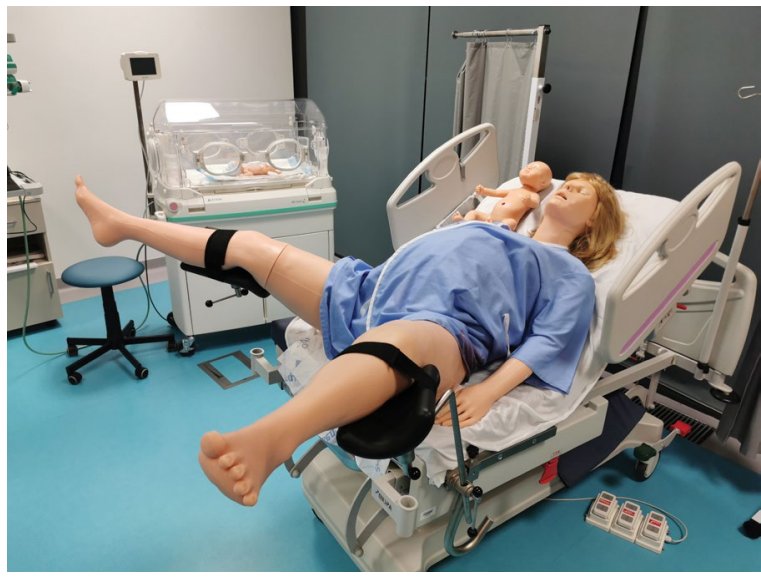

Figure 3. Human Patient's Simulator

was very wide - from chest compressions to deep veins cannulation. This example shows that simulation can go far beyond the walls of teaching rooms [13].

One of the simulation techniques that most faithfully reflects the doctor's working conditions is the use of a standardized patient (SP). His role is performed by an actor who plays the role of a patient. SP can be both volunteers and full-time employees. Some universities organize training, during which SP work with actors, psychologists and healthcare professionals. SP should be prepared to fulfil the role of the patient and therefore must have appropriate knowledge about the patient's life, current chief complaints and past medical history. Introducing SP into the simulation gives the opportunity to teach not only the correct diagnosis of disease entities, but also a professional approach to the patient, verbal and non-verbal communication, the ability to break bad news, and to deal with a difficult patient.

\section{TEACHER PARTICIPATION IN SIMULATION}

The role of the teacher leading the scenario varies depending on the technique or method chosen. In low fidelity simulation, the teacher's task is to present the activity and supervise their correct performance by each student. Therefore, the lecturer must be familiar with the equipment used, the type of trainer and the procedure itself. High fidelity simulation is a bit more demanding because it involves the need to operate the simulator. Learning objectives are achieved by creating a scenario according to which the exercise will run. The duration of the scenario varies from 10-20 minutes. Depending on the learning objectives, it is possible to create an environment for the patient's room, operating theatre, delivery room, ambulance, apartment or street. Simulation centres are most often equipped with properly prepared rooms imitating real conditions. The benefit of these classes is to familiarize the students with the conditions in which he or she will find himself performing professional activities. 


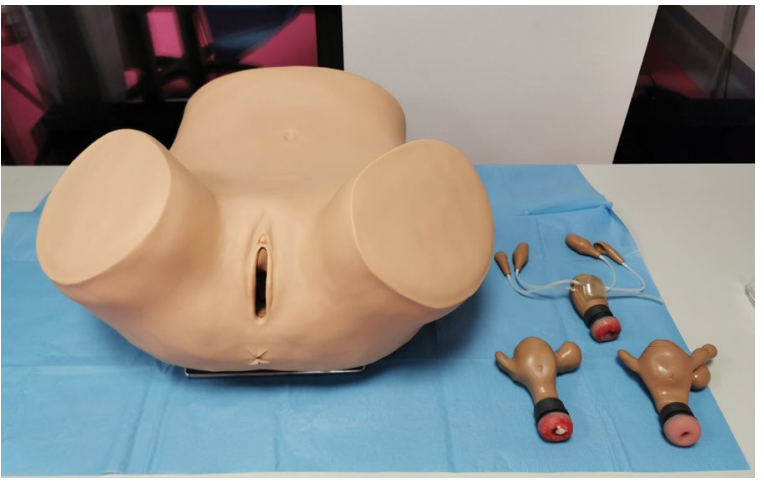

Figure 4. Speculum examination trainer

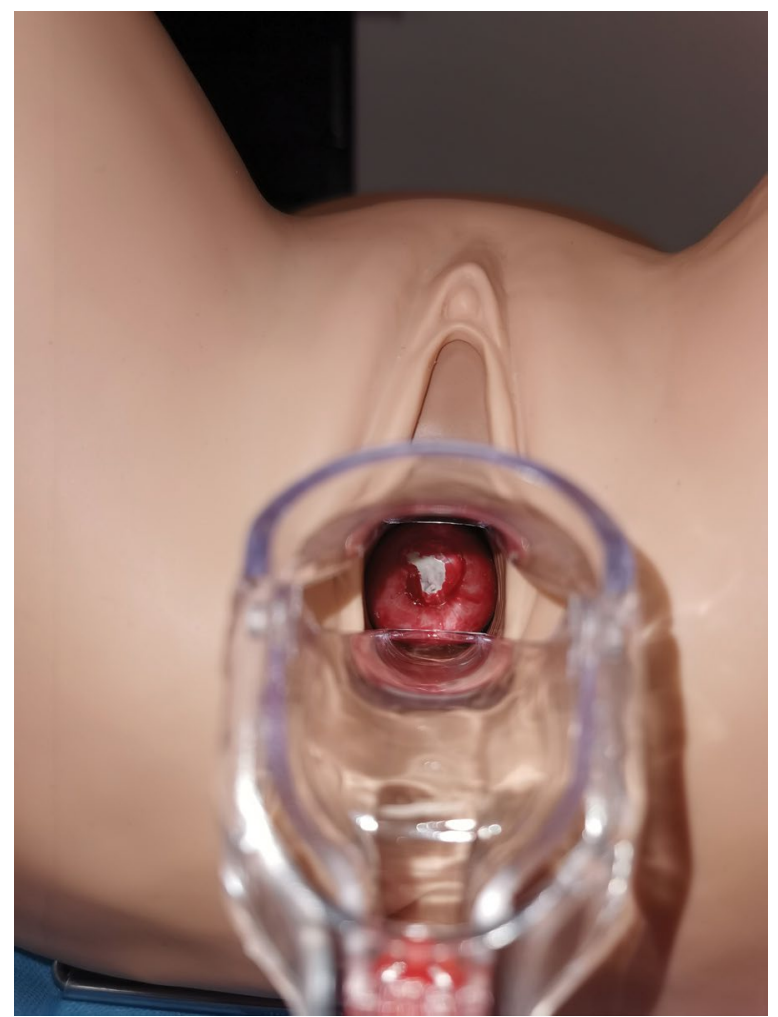

Figure 5. Speculum examination trainer - interior view

Student's work in the simulation room should take place without the teacher's direct presence. The person running the scenario should be in the control room and react to the student's activities by changing the simulator's vital signs. Possible negative consequences resulting from a mistake should occur during the scenario, so that the student is aware of them and has a chance to correct them. Concerning students' decisions, the priority is to make the scenario the basis for further reflection. Safe ways of making mistakes in simulated conditions without risking the health and life of patients is impossible in teaching at the patient's bedside.
Each scenario may be recorded and then presented to students during debriefing. This is the most important part of the simulation. Students together with the teacher analyse their activities. During debriefing the good and bad elements of the procedure should be discussed. The student should draw conclusions for the future. It is possible only when, independently or guided by the teacher, using clinical reasoning, he or she finds the essence of the problem. An important task of the lecturer is to create safe conditions both during training and in the following debriefing.

\section{PATIENT EXAMINATION}

The advantage of the simulation method is the ability to learn how to perform the correct examination before the start of clinical classes. There are papers presenting that $33 \%$ of medical graduates have never conducted a gynaecological examination [14]. According to patients, the consent or refusal of a vaginal examination was influenced by factors such as: gender (with a predominance of women), age (for the benefit of older students), less formal behaviour and past gynaecological examination experience [15].

Dinh et al. demonstrated the benefits of teaching medical students to perform ultrasound examinations using a standardized patient [16]. Whereas Nitsche et al. [17] concluded that $73 \%$ of third-year students were able to correctly assess the degree of cervical dilatation with an accuracy of $1 \mathrm{~cm}$ after simulation training with the use of a trainer. A trainer for teaching per vaginam examination was presented on figures 4 and 5 .

The best method to learn breast examination is to use hybrid simulation. It is a combination of the two methods described earlier, where the standardized patient puts on a breast trainer. A student not only performs palpation, but also interacts with a patient. The superiority of this method over testing the trainer alone was demonstrated both in terms of change detection and student satisfaction [18].

\section{LEARNING TEAM-WORK AND INTERPERSONAL COMMUNICATION}

Patient safety during life-threatening situations largely depends on the effectiveness of interdisciplinary teams. In 1999, a landmark report was published, which highlighted medical errors and patient safety. The committee that issued this document states that those responsible for the organization of healthcare must develop programs based on team training, especially when thinking about medics working in critical care [19].

Such a team cannot work effectively based only on the procedures, excellent equipment and technical skills of team members. It is important that people with different medical background participate in one training. Australian researchers have shown a significant improvement in 
test results after joint classes preceded by a lecture and instructional video. This form of training was very positively assessed by students. On the other hand, in the opinion of working medics, it allows them to better treat obstetric emergencies [20, 21].

In one of the papers published in 2018, the authors indicated that simulation allows better separation of roles in an interdisciplinary team and acquisition of good practices such as mutual respect [22]. Researchers from the Netherlands found that thanks to the creation of interdisciplinary teams and training based on simulation, the quality of life, quality of health education as well as the quality of medical care during pregnancy are increased [23]. It has also been proven that simulation-based training is an effective strategy for improving communication skills between team members and between the doctor and the patient's family [24].

Draycott et al. assessed the impact of joint training of anaesthesiologists, obstetricians and midwives on reduction in perinatal asphyxia and neonatal hypoxic-ischemic encephalopathy. Infants born with 5-minute Apgar score of $\leq 6$ decreased from 86.6 to 44.6 per 10,000 births [25]. The above paper indicates the indisputable value of joint exercise of students from various fields of study already at the stage of undergraduate education.

\section{SIMULATION IMPACT ON PATIENT TREATMENT RESULTS}

Medical simulation, especially low-fidelity, allows learning how to perform medical procedures in comfortable conditions and without a risk for patients. Mannell et al. [26] found that the use of high-fidelity simulation significantly increased the absorption of knowledge and practical skills related to receiving physiological delivery among medical students. Other authors specify that already two or three 45-minutes sessions during which each student had the opportunity to receive delivery twice in a session was adequate to obtain minimum competence 6 months after the training. As a result of this form of education, it is also possible to learn more effectively how to deal with shoulder distortion or the management of postpartum haemorrhage [27-29].

After training medical staff from the delivery ward, which used the method of medical simulation, the percentage of neonates requiring assisted ventilation fell from 7.3 to 5.9. At the same time, 24-hour mortality decreased from 11.1/1000 to 7.2/1000 [30]. Moreover, previous simulation training improved management of postpartum haemorrhage reduced the incidence of this complication from $2.1 \%$ to $1.3 \%$ [31].

Two eight-hour simulation trainings conducted at one-year intervals resulted in a decrease in the number of patients requiring transfusion of five or more blood units [32].

Draycott et al. showed that the development of good training based on medical simulation has a direct impact on the safety of patients in delivery wards. They created a curriculum that aimed to focus on reducing the frequency of neonatal injuries during delivery. It turned out that the incidence of perinatal injuries decreased from $9.3 \%$ to $2.3 \%$ [33].

\section{LOSS OF KNOWLEDGE}

The human mind is not perfect. The skills acquired disappear over time. After one-day simulation training in the field of emergency obstetrics, outcomes fell after about three months and after a year there were no significant changes compared to the group that did not participate in training [34].

On the other hand, the skills of emergency management, both in obstetrics and resuscitation of neonates, acquired during training decreased at different intervals between 6 and 12 months. Adding simulation exercises immediately before students begin clinical classes, improves their ability to assimilate knowledge, slows their loss compared to the group that starts classes in a traditional way [35-36].

\section{SUMMARY AND CONCLUSIONS}

Medical simulation is a good method of teaching basic skills as well as expanding knowledge in gynaecology and obstetrics among medical students. It gives a wide range of possibilities from learning to perform simple manual activities, through more complex procedures, to managing available equipment and personnel. It should be used at the beginning of education and precede classes with the participation of patients. The greatest benefits are obtained when classes using medical simulation are repeated regularly. Starting clinical classes with a one-day course based on this method, repeating it at the end of the class and then after a year could bring positive teaching results.

\section{REFERENCES}

1. Emergency aid and medical rescue in 2016, Information note. General Statistical Office, 2017. https://stat.gov.pl/files/gfx/portalinformacyjny/pl/defaultaktualnosci/5513/14/1/1/pomoc_dorazna_i_ratownictwo_medyczne_w_2016_r.pdf (5.03.2019).

2. American College of Obstetricians and Gynecologists, Task Force on Hypertension in Pregnancy. Hypertension in pregnancy. Report of the American College of Obstetricians and Gynecologists'Task Force on Hypertension in Pregnancy. Obstet Gynecol. 2013; 122(5): 1122-1131, doi: 10.1097/01.AOG.0000437382.03963.88, indexed in Pubmed: 24150027.

3. World Health Organization. The World Health Report 2005 - make every mother and child count. Geneva, 2005.

4. Fan D, Wu S, Wang W, et al. Prevalence of placenta previa among deliveries in Mainland China: A PRISMA-compliant systematic review and meta-analysis. Medicine (Baltimore). 2016; 95(40): e5107, doi: 10.1097/MD.0000000000005107, indexed in Pubmed: 27749592.

5. Gonda J, Kleszczynski J, Szarpak L, et al. Childbirth in the emergency medical services practice. Am J Emerg Med. 2016; 34(9): 1888, doi: 10.1016/j.ajem.2016.06.068, indexed in Pubmed: 27352983.

6. Zatoński W, Sulkowska U, Didkowska J. Kilka uwag o epidemiologii nowotworów w Polsce. Nowotwory. Journal of Oncology. 2015; 65(3): 179-196, doi: 10.5603/njo.2015.0041.

7. Sheth SS, Fader AN, Tergas Al, et al. Virtual reality robotic surgical simulation: an analysis of gynecology trainees. J Surg Educ. 2014; 71(1): 125 132, doi: 10.1016/j.jsurg.2013.06.009, indexed in Pubmed: 24411435. 
8. Owen $\mathrm{H}$, Pelosi MA. A historical examination of the Budin-Pinard phantom: what can contemporary obstetrics education learn from simulators of the past? Acad Med. 2013; 88(5): 652-656, doi: 10.1097/ACM.0b013e31828b0464, indexed in Pubmed: 23524924.

9. Beal MD, Kinnear J, Anderson CR, et al. The Effectiveness of Medical Simulation in Teaching Medical Students Critical Care Medicine: A Systematic Review and Meta-Analysis. Simul Healthc. 2017; 12(2): 104-116, doi: 10.1097/SIH.0000000000000189, indexed in Pubmed: 28704288.

10. Russell E, Hall AK, Hagel C, et al. Simulation in Canadian postgraduate emergency medicine training - a national survey. CJEM. 2018; 20(1): 132-141, doi: 10.1017/cem.2017.24, indexed in Pubmed: 28511730.

11. Elessawy M, Skrzipczyk M, Eckmann-Scholz C, et al. Integration and Validation of Hysteroscopy Simulation in the Surgical Training Curriculum. J Surg Educ. 2017; 74(1): 84-90, doi: 10.1016/j.jsurg.2016.06.007, indexed in Pubmed: 27567366.

12. Crofts JF, Bartlett C, Ellis D, et al. Training for shoulder dystocia: a trial of simulation using low-fidelity and high-fidelity mannequins. Obstet Gynecol. 2006; 108(6): 1477-1485, doi: 10.1097/01.AOG.0000246801.45977. C8, indexed in Pubmed: 17138783.

13. Puślecki M, Ligowski $M$, Dąbrowski $M$, et al. The role of simulation to support donation after circulatory death with extracorporeal membrane oxygenation (DCD-ECMO). Perfusion. 2017; 32(8): 624-630, doi: 10.1177/0267659117716533, indexed in Pubmed: 28653554

14. Bhoopatkar H, Wearn A, Vnuk A. Medical students' experience of performing female pelvic examinations: Opportunities and barriers. Aust N Z J Obstet Gynaecol. 2017; 57(5): 514-519, doi: 10.1111/ajo.12634, indexed in Pubmed: 28488309.

15. Armitage AJ, Cahill DJ. Medical students and intimate examinations: What affects whether a woman will consent? Med Teach. 2018; 40(12): 1281-1286, doi: 10.1080/0142159X.2018.1428736, indexed in Pubmed: 29385938.

16. Dinh ViAm, Frederick J, Bartos R, et al. Effects of ultrasound implementation on physical examination learning and teaching during the first year of medical education. J Ultrasound Med. 2015; 34(1): 43-50, doi: 10.7863/ultra.34.1.43, indexed in Pubmed: 25542938.

17. Nitsche JF, Shumard KM, Fino NF, et al. Effectiveness of Labor Cervical Examination Simulation in Medical Student Education. Obstet Gynecol. 2015; 126 Suppl 4: 13S-20S, doi: 10.1097/AOG.0000000000001027, indexed in Pubmed: 26375554.

18. Nassif J, Sleiman AK, Nassar AH, et al. Hybrid Simulation in Teaching Clinical Breast Examination to Medical Students. J Cancer Educ. 2019; 34(1): 194-200, doi: 10.1007/s13187-017-1287-3, indexed in Pubmed: 29019167.

19. Kohn LD, Corrigan JM, Donaldson MS. To Err Is Human: Building a Safer Health System. Committee on Quality of Health Care in America, Institute of Medicine. 2000

20. Kumar A, Nestel D, East $C$, et al. Embedding assessment in a simulation skills training program for medical and midwifery students: A pre- and post-intervention evaluation. Aust N Z J Obstet Gynaecol. 2018; 58(1): 40-46, doi: 10.1111/ajo.12659, indexed in Pubmed: 28656616.

21. Störr A, König-Bachmann M, Schwarz C. [Simulation Training in Obstetrics: Survey of participants in a low-fidelity training]. Z Geburtshilfe Neonatol. 2017; 221(3): 137-144, doi: 10.1055/s-0043-110055, indexed in Pubmed: 28666306.

22. Ruyak SL, Migliaccio L, Levi $A$, et al. Role development in midwifery education: A place for simulation. Midwifery. 2018; 59: 141-143, doi: 10.1016/j.midw.2018.01.021, indexed in Pubmed: 29427726.
23. Truijens SEM, Banga FR, Fransen AF, et al. The Effect of Multiprofessional Simulation-Based Obstetric Team Training on Patient-Reported Quality of Care: A Pilot Study. Simul Healthc. 2015; 10(4): 210-216, doi: 10.1097/SIH.0000000000000099, indexed in Pubmed: 26222503.

24. Dadiz R, Weinschreider J, Schriefer J, et al. Interdisciplinary simulation-based training to improve delivery room communication. Simul Healthc. 2013; 8(5): 279-291, doi: 10.1097/SIH.0b013e31829543a3, indexed in Pubmed: 23842120.

25. Draycott $\mathrm{T}$, Sibanda $\mathrm{T}$, Owen $\mathrm{L}$, et al. Does training in obstetric emergencies improve neonatal outcome? BJOG. 2006; 113(2): 177-182, doi: 10.1111/j.1471-0528.2006.00800.x, indexed in Pubmed: 16411995.

26. Mannella P, Antonelli R, Montt-Guevara M, et al. Simulation of childbirth improves clinical management capacity and self-confidence in medical students. BMJ Simulation and Technology Enhanced Learning. 2018; 4(4): 184-189, doi: 10.1136/bmjstel-2017-000259.

27. Nitsche JF, Butler TR, Shew AW, et al. Optimizing the amount of simulation training used to teach vaginal delivery skills to medical students. Int J Gynaecol Obstet. 2018; 140(1): 123-127, doi: 10.1002/ijgo.12329, indexed in Pubmed: 28941280.

28. Kordi M, Erfanian F, Fakari FR, et al. The comparison the effect of training by means of simulation and oral method on midwives' skill in management of shoulder dystocia. J Educ Health Promot. 2017; 6: 50, doi: 10.4103/jehp.jehp 115 15, indexed in Pubmed: 28616417.

29. Amod H, Brysiewicz P. Developing, implementing and evaluating a simulation learning package on post-partum haemorrhage for undergraduate midwifery students in KwaZulu-Natal* . Health SA Gesondheid. 2017; 22: 194-201, doi: 10.4102/hsag.v22i0.993.

30. Mduma $\mathrm{E}$, Ersdal $\mathrm{H}$, Svensen $\mathrm{E}$, et al. Frequent brief on-site simulation training and reduction in 24-h neonatal mortality--an educational intervention study. Resuscitation. 2015; 93: 1-7, doi: 10.1016/j.resuscitation.2015.04.019, indexed in Pubmed: 25957942.

31. Nelissen E, Ersdal H, Mduma E, et al. Clinical performance and patient outcome after simulation-based training in prevention and management of postpartum haemorrhage: an educational intervention study in a low-resource setting. BMC Pregnancy Childbirth. 2017; 17(1): 301, doi: 10.1186/s12884-017-1481-7, indexed in Pubmed: 28893211.

32. Egenberg S, Øian P, EggebøTM, et al. Changes in self-efficacy, collective efficacy and patient outcome following interprofessional simulation training on postpartum haemorrhage. J Clin Nurs. 2017; 26(19-20): 3174-3187, doi: 10.1111/jocn.13666, indexed in Pubmed: 27874995.

33. Draycott TJ, Crofts JF, Ash JP, et al. Improving neonatal outcome through practical shoulder dystocia training. Obstet Gynecol. 2008; 112(1): 14-20, doi: 10.1097/AOG.0b013e31817bbc61, indexed in Pubmed: 18591302.

34. van de Ven J, Fransen AF, Schuit E, et al. Does the effect of one-day simulation team training in obstetric emergencies decline within one year? A post-hoc analysis of a multicentre cluster randomised controlled trial. Eur J Obstet Gynecol Reprod Biol. 2017; 216: 79-84, doi: 10.1016/j. ejogrb.2017.07.020, indexed in Pubmed: 28738295.

35. Nelissen E, Ersdal H, Mduma E, et al. Helping Mothers Survive Bleeding After Birth: retention of knowledge, skills, and confidence nine months after obstetric simulation-based training. BMC Pregnancy Childbirth. 2015; 15: 190, doi: 10.1186/s12884-015-0612-2, indexed in Pubmed: 26303614.

36. Carolan-Olah M, Kruger G, Brown V, et al. Communicating out loud: Midwifery students' experiences of a simulation exercise for neonatal resuscitation. Nurse Educ Pract. 2018; 29: 8-14, doi: 10.1016/j.nepr.2017.10.027 indexed in Pubmed: 29144999. 